\title{
Increased expression of POLR3G predicts poor prognosis in transitional cell carcinoma
}

\author{
Xianhui Liu ${ }^{\text {Equal first author, } 1}$, Weiyu Zhang ${ }^{\text {Equal first author, } 1,2}{ }^{2}$ Huanrui Wang ${ }^{1,2}{ }^{2}$ Chin-Hui Lai ${ }^{1}$, Kexin Xu ${ }^{\text {Corresp., } 1}$, Hao Hu ${ }^{\text {Corresp. } 1}$ \\ ${ }^{1}$ Department of Urology, Peking University People's Hospital, Beijing, China \\ 2 Peking University Applied Lithotripsy Institute, Peking University People's Hospital, Beijing, China \\ Corresponding Authors: Kexin $\mathrm{Xu}, \mathrm{HaO} \mathrm{Hu}$ \\ Email address: cavinx@yeah.net, huhao@bjmu.edu.cn
}

Background. Previous studies have shown that RNA Polymerase III Subunit G (POLR3G) has oncogenic effects in cultured cells and mice. However, the role of POLR3G in transitional cell carcinoma (TCC) has not been reported. This study explores the potential of POLR3G as a novel molecular marker for TCC. Methods. The RNA sequencing data and clinical information of patients with TCC were downloaded from The Cancer Genome Atlas official website. Transcriptome analysis was performed as implemented in the edgeR package to explore whether POLR3G was up-regulated in TCC tissues compared to normal bladder tissues. The expression of POLR3G in bladder cancer cell line T24 and human uroepithelial cell line SV-HUC-1 were detected via quantitative real time polymerase chain reaction (qRT-PCR). Correlations between POLR3G expression and clinicopathological characteristics were analyzed using Mann-Whitney $\mathrm{U}$ test or Kruskal-Wallis $\mathrm{H}$ test.

Clinicopathological characteristics associated with overall survival were explored using the Kaplan-Meier method and Cox regression analyses. Gene set enrichment analysis (GSEA) was performed to explore the associated gene sets enriched in different POLR3G expression phenotypes and the online tool Tumor IMmune Estimation Resource (TIMER) was used to explore the correlation between POLR3G expression and tumor immune infiltration in TCC. Results. Transcriptome analysis showed that POLR3G was significantly up-regulated in TCC tissues compared to normal bladder tissues. Furthermore, qRT-PCR revealed high expression of POLR3G in T24 cells compared to SV-HUC-1 cells. Overall, POLR3G expression was associated with race, tumor status, tumor subtype, $T$ classification, and pathological stage. Kaplan-Meier survival analysis revealed that higher POLR3G expression was associated with lower overall survival. The univariate Cox regression model revealed that age at diagnosis, pathological stage, and POLR3G expression were associated with prognosis of TCC patients. Further multivariate analyses identified these three clinicopathological characteristics as independent prognostic factors for overall survival. GSEA analysis showed that several gene sets associated with tumor 
development and metastasis, including TGF- $\beta$ signaling, PI3K-AKT-mTOR signaling, and IL6JAK-STAT3 signaling, were significantly enriched in POLR3G high expression phenotype. Immune infiltration analysis revealed that the expression of POLR3G was significantly correlated with infiltrating levels of immune cells, including CD8+ T cells, neutrophils, and dendritic cells; and the expression of POLR3G was also significantly correlated with the expression of immune checkpoint molecules, such as PD1, PD-L1, PD-L2, CTLA4, LAG3, HAVCR2, and TIGIT. Conclusions. POLR3G was up-regulated in TCC and high POLR3G expression correlated with poor prognosis. POLR3G can potentially be used as a prognostic marker for TCC and might be of great value in predicting the response to immunotherapy. 


\section{Increased expression of POLR3G predicts poor} 2 prognosis in transitional cell carcinoma

3

4 Xianhui Liu ${ }^{1}$, Weiyu Zhang ${ }^{1,2}$, Huanrui Wang ${ }^{1,2}$, Chin-Hui Lai ${ }^{1}$, Kexin $\mathrm{Xu}^{1}$, Hao Hu${ }^{1}$ 5

6

7 8 9

10 Corresponding Authors:

11 Kexin $\mathrm{Xu}^{1}$

12 No.11 Xizhimen South Street, Xicheng District, Beijing, 100044, China

13 Email address: cavinx@yeah.net

14

15

${ }^{1}$ Department of Urology, Peking University People's Hospital, Beijing, China

${ }^{2}$ Peking University Applied Lithotripsy Institute, Peking University People's Hospital, Beijing, China

$\mathrm{Hao} \mathrm{Hu}^{1}$

No.11 Xizhimen South Street, Xicheng District, Beijing, 100044, China

Email address: huhao@bjmu.edu.cn 


\section{Abstract}

21 Background. Previous studies have shown that RNA Polymerase III Subunit G (POLR3G) has

22

23

24

25

26

27

28

29

30

31

32

33

34

35

36

37

38

39

40

41

42

43

44

45

46

47

48

49

50

51

52

53

54

55

56

57

58

59

oncogenic effects in cultured cells and mice. However, the role of POLR3G in transitional cell carcinoma (TCC) has not been reported. This study explores the potential of POLR3G as a novel molecular marker for TCC.

Methods. The RNA sequencing data and clinical information of patients with TCC were downloaded from The Cancer Genome Atlas official website. Transcriptome analysis was performed as implemented in the edgeR package to explore whether POLR3G was up-regulated in TCC tissues compared to normal bladder tissues. The expression of POLR3G in bladder cancer cell line T24 and human uroepithelial cell line SV-HUC-1 were detected via quantitative real time polymerase chain reaction (qRT-PCR). Correlations between POLR3G expression and clinicopathological characteristics were analyzed using Mann-Whitney U test or Kruskal-Wallis $\mathrm{H}$ test. Clinicopathological characteristics associated with overall survival were explored using the Kaplan-Meier method and Cox regression analyses. Gene set enrichment analysis (GSEA) was performed to explore the associated gene sets enriched in different POLR3G expression phenotypes and the online tool Tumor IMmune Estimation Resource (TIMER) was used to explore the correlation between POLR3G expression and tumor immune infiltration in TCC. Results. Transcriptome analysis showed that POLR3G was significantly up-regulated in TCC tissues compared to normal bladder tissues. Furthermore, qRT-PCR revealed high expression of POLR3G in T24 cells compared to SV-HUC-1 cells. Overall, POLR3G expression was associated with race, tumor status, tumor subtype, $\mathrm{T}$ classification, and pathological stage. Kaplan-Meier survival analysis revealed that higher POLR3G expression was associated with lower overall survival. The univariate Cox regression model revealed that age at diagnosis, pathological stage, and POLR3G expression were associated with prognosis of TCC patients. Further multivariate analyses identified these three clinicopathological characteristics as independent prognostic factors for overall survival. GSEA analysis showed that several gene sets associated with tumor development and metastasis, including TGF- $\beta$ signaling, PI3K-AKTmTOR signaling, and IL6-JAK-STAT3 signaling, were significantly enriched in POLR3G high expression phenotype. Immune infiltration analysis revealed that the expression of POLR3G was significantly correlated with infiltrating levels of immune cells, including CD8+ T cells, neutrophils, and dendritic cells; and the expression of POLR3G was also significantly correlated with the expression of immune checkpoint molecules, such as PD1, PD-L1, PD-L2, CTLA4, LAG3, HAVCR2, and TIGIT.

Conclusions. POLR3G was up-regulated in TCC and high POLR3G expression correlated with poor prognosis. POLR3G can potentially be used as a prognostic marker for TCC and might be of great value in predicting the response to immunotherapy.

\section{Introduction}

Bladder cancer is the 7 th most commonly diagnosed cancer in males and the 11 th most commonly diagnosed cancer when both genders are considered (Ferlay et al., 2013). In 2020, an

Peer) reviewing PDF | (2020:06:50549:1:1:NEW 21 Sep 2020) 
60

61

62

63

64

65

66

67

68

69

70

71

72

73

74

75

76

77

78

79

80

81

82

83

84

85

86

87

88

89

90

91

92

93

94

95

96

97

98

estimated 81,400 new cases of bladder cancer (62,100 men; 19,300 women) will be diagnosed in the United States of America and approximately 17,980 deaths (13,050 men; 4,930 women) will occur during the same period of time (Siegel et al., 2020). Transitional cell carcinoma (TCC) is the most common histological type of bladder cancer, contributing to more than $90 \%$ of all bladder cancer cases (Witjes et al., 2020). Approximately $75 \%$ of patients with bladder cancer are present with non-muscle-invasive bladder cancer (NMIBC) at the initial diagnosis, while the remaining $25 \%$ of patients are present with muscle-invasive bladder cancer (MIBC) or metastatic bladder cancer (Witjes et al., 2020). The standard treatment for NMIBC is trans-urethral resection of bladder tumor (TURBT) followed by intravesical chemotherapy or bacillus Calmette-Guérin (BCG) immunotherapy depending on risk stratifications. For MIBC, on the other hand, neoadjuvant chemotherapies followed by radical cystectomy are first line recommendations. However, the prognosis for MIBC is poor even with effective treatments. The five-year recurrence-free survival rate was $89 \%$ for patients with T2 tumors, $50 \%$ for patients with $\mathrm{T} 4$ tumors, and $35 \%$ for patients with lymph node metastasis respectively (Stein et al., 2001). Patients with NMIBCs have better prognoses, however, high grade NMIBC has a $70 \%$ recurrence rate with a 15\%-40\% risk of progression after five years (Kashif Khan et al., 2014).

For TCC, the most important histopathological prognostic variables are tumor stage and lymph node status (Dutta et al., 2016; Stein et al., 2001). However, no predictive molecular markers are routinely used in clinical practice. Thus, identifying effective markers is essential for predicting prognoses and directing treatments for patients with TCC. Although previous studies have revealed that RNA Polymerase III Subunit G (POLR3G) overexpression can have oncogenic effects in cultured cells and mice (Haurie et al., 2010; Khattar et al., 2016), its role in TCC has still not been reported. Herein, the aim of this study is to evaluate the correlation between POLR3G and prognoses of patients with TCC.

\section{Materials \& Methods}

\section{Data acquisition}

The RNA sequencing (RNA-seq) data (Workflow types: HTSeq-FPKM; HTSeq-Counts) and corresponding clinical information of patients with TCC (Project: TCGA-BLCA, Disease type: transitional cell papillomas and carcinomas) were downloaded from GDC Data Portal (https://portal.gdc.cancer.gov/). Counts data were used for transcriptome analysis. TPM data were calculated based on FPKM data, and were used for further analysis. Only patients with both RNA-seq data and survival information were included in this study.

\section{Cell lines and cell culture}

Human bladder cancer cell line T24 and immortalized normal urothelial cell line SV-HUC1 were purchased from National Infrastructure of Cell Line Resource (Beijing, China). Cell lines were maintained in Roswell Park Memorial Institute (RPMI) 1640 medium (Gibco) 
99

100

101

102

103

104

105

106

107

108

109

110

111

112

113

114

115

116

117

118

119

120

121

122

123

124

125

126

127

128

129

130

131

132

133

134

135

136

137

138

supplemented with $10 \%$ fetal bovine serum (Gibco) and 1\% penicillin/streptomycin (Gibco). All cells were maintained in a humidified atmosphere with $5 \% \mathrm{CO} 2$ at $37{ }^{\circ} \mathrm{C}$.

\section{RNA extraction and qRT-PCR}

Total RNA was extracted from cells using the RNA simple Total RNA Kit (Tiangen). FastQuant RT Kit (Tiangen) was used for cDNA synthesis. The quantitative real time polymerase chain reactions (qRT-PCR) were performed using KAPA SYBR FAST Universal q-PCR Kit (KAPA). The relative mRNA levels of genes were calculated using cycle threshold (CT) methods, and $\beta$ actin was used as an endogenous control. Three replicate samples were studied for detection of mRNA expression. The primers were listed below: POLR3G (forward): 5'CGCAGGCAAAGGCACAC-3'; POLR3G (reverse): 5'-CCTCTTTTTTCCAATTCCTCCA-3'; $\beta$-actin (forward): 5'-CCAACCGCGAGAAGATGA-3'; $\beta$-actin (reverse): 5 'CCAGAGGCGTACAGGGATAG-3'.

\section{Gene set enrichment analysis}

Gene set enrichment analysis (GSEA) is widely applied to determine whether predefined gene sets are differentially expressed in different phenotypes. (Subramanian et al., 2005) To identify signaling pathways that are differentially activated in TCCs, we conducted GSEA analysis between high and low POLR3G expression groups. GSEA analysis was performed using GSEA software (version 4.0.3). The h.all.v7.1.symbols.gmt (hallmark) dataset was obtained from the Molecular Signatures Database (MsigDB) (Liberzon et al., 2015). Enrichment analysis was performed by default weighted enrichment statistics, with the random combinatorial count set as 1,000 . Gene sets were judged as significantly enriched by $\mathrm{P}<0.05$ as well as false discovery rates $(\mathrm{FDR})<0.25$.

\section{Tumor infiltrating immune cells and immune checkpoint molecule expression analysis} Tumor IMmune Estimation Resource (TIMER) is a web server for comprehensive analysis of tumor-infiltrating immune cells, which applies a previously published statistical approach called the deconvolution that uses the gene expression profiles to produce an inference on the number of tumor-infiltrating immune cells ( $\mathrm{Li}$ et al., 2016). Survival module was used to explore the association between immune cell infiltration (B cells, CD4+ T cells, CD8+ T cells, neutrophils, macrophages, and dendritic cells) and clinical outcome in bladder cancer. Gene module was used to explore the correlations between the expression of POLR3G and immune cell infiltration. Correlation module was used to explore the correlations between POLR3G expression and immune checkpoint molecule expression, including PDCD1 (also known as PD1), CD274 (also known as PD-L1), PDCD1LG2 (also known as PD-L2), CTLA4, LAG3, HAVCR2, and TIGIT.

\section{Statistical analysis}

The data processing and further statistical analyses were performed using R (v.3.6.3).

Transcriptome analysis of the differentially expressed genes (DEGs) in the TCC tissues and 
139

140

141

142

143

144

145

146

147

148

149

150

151

152

153

154

155

156

157

158

159

160

161

162

163

164

165

166

167

168

169

170

171

172

173

174

175

176

177

normal bladder tissues was performed using edgeR package (Robinson et al., 2010). The differential expression of POLR3G between T24 cells and SV-HUC-1 cells was analyzed via independent $t$ test. The relationships between clinicopathological characteristics and POLR3G expression were analyzed using the Mann-Whitney U test or Kruskal-Wallis H test. The KaplanMeier method and Cox regression models were used to explore the influence of POLR3G expression on overall survival along with other clinicopathological characteristics (age at diagnosis, gender, race, and pathological stage). The cut-off value of POLR3G expression was determined by its median value. $\mathrm{P}<0.05$ was considered to indicate a statistically significant difference.

\section{Results}

\section{Clinical characteristics}

The clinical characteristics of 404 patients with TCC in The Cancer Genome Atlas (TCGA) are presented in Table 1. There were 299 (74.01\%) male patients and 105 (25.99\%) female patients with a median age of 69 years old at the time of diagnosis. Race information was available for 388 patients, among which 322 (82.99\%) patients were white, $43(11.08 \%)$ were Asian, and 23 (5.93\%) were black or African American. At least 202 (63.72\%) patients were tumor free while $115(36.28 \%)$ patients still had tumors. Overall, $2(0.50 \%)$ of the patients showed stage I, 129 (32.09\%) stage II, 137 (34.08\%) stage III, and 134 (33.33\%) stage IV. Among 363 patients diagnosed with clear N stage, 129 (35.54\%) had lymph node metastases. From 205 patients diagnosed with clear M stage, 11 (5.37\%) had distant metastases. Median follow-up for subjects alive at last contact was 21.3 months (range 0-169 months).

\section{POLR3G was up-regulated in multiple cancer types including TCC}

TIMER analyses revealed that POLR3G expression was up-regulated in multiple cancer types, including cholangiocarcinoma, colon adenocarcinoma, esophageal carcinoma, kidney renal clear cell carcinoma. (Fig. 1A). RNA-Seq differential expression analysis revealed that 2,211 genes were up-regulated $(\log 2 \mathrm{FC}>1$, and FDR $<0.01)$ in TCC tissues compared to normal bladder tissues, including POLR3G $(\log 2 \mathrm{FC}=1.038, \mathrm{FDR}=0.006)$, and 1,853 genes were downregulated $(\log 2 \mathrm{FC}<-1$, and FDR $<0.01)$. (Fig.1B and Table $\mathrm{S} 1)$. Furthermore, qRT-PCR results showed higher expression levels of POLR3G in T24 cells compared to SV-HUC-1 cells ( $\mathrm{P}=$ 0.004; Fig. 1C).

\section{Relationship between POLR3G expression and clinicopathological characteristics}

Expression levels of POLR3G were strongly correlated with T classification (T1-2 vs. T3-4, P= 0.001; Fig. 2A), pathological stage (stage I-II vs. stage III-IV, P =0.005; Fig. 2B), tumor status (tumor free vs. with tumor, $\mathrm{P}=0.001$; Fig. $2 \mathrm{C}$ ), tumor subtype (papillary vs. non-papillary, $\mathrm{P}<$ 0.001 ; Fig. 2D), and race ( $<0.001$; Fig. 2E). No statistically significant differences were observed between groups stratified by age ( $\leq 60$ years old vs. $>60$ years old, $P=0.113$; Fig. $2 \mathrm{~F})$, 
178

179

180

181

182

183

184

185

186

187

188

189

190

191

192

193

194

195

196

197

198

199

200

201

202

203

204

205

206

207

208

209

210

211

212

213

214

215

216

217

gender (female vs. male, $\mathrm{P}=0.072$; Fig. $2 \mathrm{G}$ ), lymph node metastasis (positive vs. negative, $\mathrm{P}=$ 0.201; Fig. $2 \mathrm{H}$ ), and distant metastasis (positive vs. negative, $\mathrm{P}=0.056$; Fig. 2I).

\section{Survival outcomes and Cox regression analysis}

Kaplan-Meier survival analysis revealed that higher expression of POLR3G was associated with worse prognoses $(\mathrm{P}=0.002$; Fig. 1D). The univariate Cox regression model revealed that age at diagnosis $(\mathrm{HR}=1.03,95 \% \mathrm{CI}=1.02$ to $1.05, \mathrm{P}<0.001)$, pathological stage $(\mathrm{HR}=1.71,95 \% \mathrm{CI}$ $=1.41$ to $2.08, \mathrm{P}<0.001)$, and POLR3G expression $(\mathrm{HR}=1.04,95 \% \mathrm{CI}=1.01$ to $1.07, \mathrm{P}=$ 0.02) were associated with overall survival of patients with TCC. Furthermore, multivariate Cox regression after adjustment indicated that age at diagnosis $(\mathrm{HR}=1.03,95 \% \mathrm{CI}=1.02$ to $1.05, \mathrm{P}$ $<0.001)$, pathological stage $(\mathrm{HR}=1.77,95 \% \mathrm{CI}=1.45$ to $2.17, \mathrm{P}<0.001)$, and POLR3G expression $(\mathrm{HR}=1.05,95 \% \mathrm{CI}=1.02$ to $1.08, \mathrm{P}=0.001)$ were independent prognostic factors for overall survival in patients with TCC (Table 2, Fig. 3).

\section{Gene sets enriched in POLR3G high expression phenotype}

In the hallmark dataset, 41 gene sets were significantly enriched in POLR3G high expression phenotype (Table 3). Several of the gene sets are associated with oncogenesis, progression, and metastasis of cancer, such as mitotic spindle, hypoxia, Kras signaling up, PI3K-AKT-mTOR signaling, IL6-JAK-STATS3 signaling, mTORC1 signaling, TNF- $\alpha$ signaling via $\mathrm{NF}-\kappa \mathrm{B}$, inflammatory response, and Myc targets v1(Fig. 4A-I).

\section{POLR3G expression was associated with levels of immune cell infiltration and immune} checkpoint molecule expression

Analysis of TIMER survival module indicated that the infiltration of CD8+ T cells is related to the cumulative survival rate in TCC $(\mathrm{P}=0.006$, Fig. 5A). Gene module analysis revealed that POLR3G expression was negatively correlated with tumor purity $($ cor $=-0.178, \mathrm{P}=6.02 \mathrm{e}-04)$ and positively correlated with infiltrating levels of $\mathrm{CD} 8+\mathrm{T}$ cell ( cor $=0.317, \mathrm{P}=5.70 \mathrm{e}-10)$, neutrophil cells ( cor $=0.237, \mathrm{P}=5.12 \mathrm{e}-06)$, and dendritic cells ( cor $=0.399, \mathrm{P}=2.15 \mathrm{e}-15)$ in TCC (Fig. 5B). Moreover, Correlation module analysis revealed that the expression of POLR3G was significantly correlated with the expression of immune checkpoint molecules including PDCD1 (cor $=0.227, \mathrm{P}=3.57 \mathrm{e}-06), \mathrm{CD} 274$ (cor $=0.455, \mathrm{P}=3.18 \mathrm{e}-22)$, PDCD1LG2 (cor $=$ 0.399, $\mathrm{P}=4.60 \mathrm{e}-17), \mathrm{CTLA}-4(\mathrm{cor}=0.279, \mathrm{P}=9.87 \mathrm{e}-09), \mathrm{LAG} 3($ cor $=0.344, \mathrm{P}=8.32 \mathrm{e}-13)$, HAVCR2 (cor $\left.=0.312, \mathrm{P}=1.18 \mathrm{e}^{-10}\right)$, and TIGIT(cor $\left.=0.255, \mathrm{P}=1.78 \mathrm{e}-07\right)$ (Fig. 5C).

\section{Discussion}

Several studies have investigated prognostic biomarkers for TCC, such as FGF2 (Shariat et al., 2010), UHRF1(Unoki et al., 2009), and GRIA1(Tilley et al., 2017). However, there are still no ideal predictive molecule for clinical application. This study demonstrates that POLR3G is a potentially useful biomarker for predicting prognosis of TCC. 
218 POLR3G is an RNA polymerase III peripheral subunit that synthesizes small RNAs, such as 5S 219 rRNA, tRNAs, and some microRNAs (Haurie et al., 2010). POLR3G plays a role in sensing and 220 limiting infection by intracellular bacteria and DNA viruses, acts as a nuclear and cytosolic DNA

221

222

223

224

225

226

227

228

229

230

231

232

233

234

235

236

237

238

239

240

241

242

243

244

245

246

247

248

249

250

251

252

253

254

255

256 sensor involved in innate immune responses, and is also essential for the maintenance of stem cell state (Ablasser et al., 2009; Chiu et al., 2009; Lund et al., 2017; Wong et al., 2011). Several studies have described the links between POLR3G and cancer. For example, Durrieu-Gaillard et al. reported that POLR3G expression was strongly up-regulated during the process of tumoral transformation in the human lung fibroblast cell line IMR90 model system (Durrieu-Gaillard et al., 2018). Haurie et al. showed that overexpression of POLR 3 G in IMR90 increased the expression of genes associated with tumor growth and metastasis, including S100A4, RFC2, EZR, and RAC1, and reduced the expression of tumor-suppressing genes, such as PFDN5 and KLF6 (Haurie et al., 2010). Another study (Petrie et al., 2019) found that the expression of POLR3G was up to three-fold higher in prostate tumors compared to normal adjacent samples. Similar results were observed at the cellular level; POLR3G expression was elevated in the prostate cancer cell line PC-3 compared to the immortalized healthy prostate epithelium cell line PNT2C2. In addition, knockdown of POLR3G triggered the proliferative arrest of PC-3.

Results of this study revealed that POLR3G was highly expressed in multiple cancer types, including TCC, and qRT-PCR further confirmed that POLR3G was elevated in T24 cells compared to SV-HUC-1 cells. These findings are indicative of a cumulative alteration of POLR3G expression during TCC tumorigenesis. The traditional perspective of TCC tumorigenesis postulates that TCCs arise via two different but overlapping pathways: papillary pathway and non-papillary pathway (Dinney et al., 2004). We found that non-papillary TCCs exhibited higher POLR3G expression compared to papillary TCCs. Therefore, POLR3G might play different roles in these two pathways. We also found that high POLR3G expression was positively correlated with high $\mathrm{T}$ classification, advanced clinical stage, and tumor recurrence, which are strongly correlated with poor prognosis in patients with TCC. More importantly, further univariate and multivariate analysis identified POLR3G expression as an independent prognostic factor for overall survival.

We conducted GSEA analysis to investigate the relationship between POLR3G and gene signatures in TCCs. Our results showed that 41 gene sets were significantly enriched in the POLR3G high expression group, including mitotic spindle, Inflammatory response, TGF- $\beta$ signaling, epithelial mesenchymal transition, PI3K-AKT-mTOR signaling, and IL-6-JAKSTATS3 signaling. Several of these pathways are associated with oncogenesis, progression, and metastasis of cancer, suggesting that POLR3G expression contributes to the development, progression, and prognosis of TCC. However, the regulatory mechanism needs to be further elucidated. 
257

258

259

260

261

262

263

264

265

266

267

268

269

270

271

272

273

274

275

276

277

278

279

280

281

282

283

284

285

286

287

288

289

290

291

292

293

294

295

296

Immunotherapy is a key treatment approach for TCC. Intravesical BCG immunotherapy has been used to treat superficial TCC for over 40 years and still represents the first-line adjuvant treatment for superficial TCC after TURBT to prevent tumor recurrence (Babjuk et al., 2019; Morales et al., 1976). Over the past decade, immune checkpoint inhibitor (ICI) immunotherapy breakthroughs have enriched the available treatment modalities for advanced TCCs.

Atezolizumab and Pembrolizumab have been approved for first-line systemic therapy for cisplatin-ineligible patients with local advanced or metastatic TCC whose tumors express PDL1(Balar et al., 2017a; Balar et al., 2017b). However, the objective response rate (ORR) to ICIs in bladder cancer patients was only 20\% (Balar et al., 2017a; Balar et al., 2017b). Thus, identifying reliable biomarkers to distinguish which patients are more likely to respond to ICI immunotherapy is crucial for the successful treatment. Previous studies have demonstrated that the level of the immune infiltration within tumors correlates with bladder cancer prognosis and is a positive prognostic indicator of response to immunotherapy (Fridman et al., 2012; Pfannstiel et al., 2019). Furthermore, the expression of immune checkpoint PD-L1 on tumors correlates with unfavorable prognosis, but can also predict the immunotherapy reactivity of patients (Thompson et al., 2007; Topalian et al., 2015). Therefore, we explored the potential role of POLR3G in immune cell infiltration within TCCs using TIMER.

First, we used the survival module to explore the association between immune infiltrate abundance and clinical outcome. Previous studies have reported that CD8+ T cells infiltration might play a positive role in the prognosis of colorectal cancer (Naito et al., 1998), triplenegative breast cancer (Vihervuori et al., 2019), and pancreatic cancer (Masugi et al., 2019). However, our results suggest that CD8+ T cell infiltration was negatively correlated with cumulative survival in TCC. Second, we used the gene module to explore the correlation between POLR3G expression and immune infiltrate abundance. Results from this analysis showed that POLR3G expression was significantly correlated with the level of infiltrating immune cells in TCC. More specifically, POLR3G expression was negatively correlated with tumor purity, and positively correlated with the infiltrating levels of CD8+ T cells, neutrophil cells, and dendritic cells in TCC. We further explored the correlations between POLR3G and immune checkpoint molecules in TCC via the correlation module. Results revealed that POLR3G expression was significantly correlated with several immune checkpoint molecules, including PDCD1, CD274, PDCD1LG2, CTLA4, LAG3, HAVCR2, and TIGIT. Taken together, these findings suggest that POLR3G contributes to the regulation of immune cell infiltration and immune checkpoint molecule expression, resulting in the suppression of anti-tumor immunity. These results provide a possible mechanistic explanation for the worse prognosis observed in patients with higher POLR3G expression.

To the best of our knowledge, this is the first study investigating the role of POLR3G in TCC. We found that POLR3G expression was an independent prognostic factor for overall survival and can potentially be used as a prognostic biomarker in TCC. However, there were some 
297 limitations to this study. First, this study was conducted using data from the public database 298 TCGA, and the clinical information was incomplete for some patients. Further investigation with 299 a larger sample size is needed to validate our findings. Second, the relationships between 300 POLR3G and immune cell infiltration were analyzed using online tools, which need to be further 301 elucidated via molecular experiments.

302

303

\section{Conclusions}

304

305

306

307

308

309

310

311

312

313

314

315

316

317

318

319

320

321

322

323

324

325

326

327

328

329

330

331

332

333

334

335

In summary, POLR3G expression was up-regulated in TCC and can potentially be used as a prognostic marker. In addition, the expression of POLR3G was associated with levels of immune cell infiltration and the expression of immune checkpoint molecules in TCC, suggesting potential value for predicting patient response to ICI immunotherapy.

\section{Acknowledgements}

The results shown here are mostly based upon data generated by the TCGA Research Network: http://cancergenome.nih.gov/.

\section{References}

Ablasser A, Bauernfeind F, Hartmann G, Latz E, Fitzgerald KA, and Hornung V. 2009. RIG-Idependent sensing of poly(dA:dT) through the induction of an RNA polymerase IIItranscribed RNA intermediate. Nature immunology 10:1065-1072 DOI: 10.1038/ni.1779.

Babjuk M, Burger M, Compérat EM, Gontero P, Mostafid AH, Palou J, van Rhijn BWG, Rouprêt M, Shariat SF, Sylvester R, Zigeuner R, Capoun O, Cohen D, Escrig JLD, Hernández V, Peyronnet B, Seisen T, and Soukup V. 2019. European Association of Urology Guidelines on Non-muscle-invasive Bladder Cancer (TaT1 and Carcinoma In Situ) - 2019 Update. European urology 76:639-657 DOI: 10.1016/j.eururo.2019.08.016.

Balar AV, Castellano D, O'Donnell PH, Grivas P, Vuky J, Powles T, Plimack ER, Hahn NM, de Wit R, Pang L, Savage MJ, Perini RF, Keefe SM, Bajorin D, and Bellmunt J. 2017 a. First-line pembrolizumab in cisplatin-ineligible patients with locally advanced and unresectable or metastatic urothelial cancer (KEYNOTE-052): a multicentre, single-arm, phase 2 study. The Lancet Oncology 18:1483-1492 DOI: 10.1016/S1470-2045(17)306162.

Balar AV, Galsky MD, Rosenberg JE, Powles T, Petrylak DP, Bellmunt J, Loriot Y, Necchi A, Hoffman-Censits J, Perez-Gracia JL, Dawson NA, van der Heijden MS, Dreicer R, Srinivas S, Retz MM, Joseph RW, Drakaki A, Vaishampayan UN, Sridhar SS, Quinn DI, Durán I, Shaffer DR, Eigl BJ, Grivas PD, Yu EY, Li S, Kadel EE, Boyd Z, Bourgon R, Hegde PS, Mariathasan S, Thåström A, Abidoye OO, Fine GD, and Bajorin DF. 2017b. Atezolizumab as first-line treatment in cisplatin-ineligible patients with locally advanced and metastatic urothelial carcinoma: a single-arm, multicentre, phase 2 trial. Lancet (London, England) 389:67-76 DOI: 10.1016/S0140-6736(16)32455-2. 
336

337

338

339

340

341

342

343

344

345

346

347

348

349

350

351

352

353

354

355

356

357

358

359

360

361

362

363

364

365

366

367

368

369

370

371

372

373

Chiu Y-H, Macmillan JB, and Chen ZJ. 2009. RNA polymerase III detects cytosolic DNA and induces type I interferons through the RIG-I pathway. Cell 138:576-591 DOI: 10.1016/j.cell.2009.06.015.

Dinney CPN, McConkey DJ, Millikan RE, Wu X, Bar-Eli M, Adam L, Kamat AM, SiefkerRadtke AO, Tuziak T, Sabichi AL, Grossman HB, Benedict WF, and Czerniak B. 2004. Focus on bladder cancer. Cancer cell 6:111-116 DOI: 10.1016/j.ccr.2004.08.002.

Durrieu-Gaillard S, Dumay-Odelot H, Boldina G, Tourasse NJ, Allard D, André F, Macari F, Choquet A, Lagarde P, Drutel G, Leste-Lasserre T, Petitet M, Lesluyes T, LartigueFaustin L, Dupuy J-W, Chibon F, Roeder RG, Joubert D, Vagner S, and Teichmann M. 2018. Regulation of RNA polymerase III transcription during transformation of human IMR90 fibroblasts with defined genetic elements. Cell cycle (Georgetown, Tex) 17:605615 DOI: 10.1080/15384101.2017.1405881.

Dutta R, Abdelhalim A, Martin JW, Vernez SL, Faltas B, Lotan Y, and Youssef RF. 2016. Effect of tumor location on survival in urinary bladder adenocarcinoma: A population-based analysis. Urologic oncology 34:531.e531-531.e536 DOI: 10.1016/j.urolonc.2016.06.009.

Ferlay J, Steliarova-Foucher E, Lortet-Tieulent J, Rosso S, Coebergh JWW, Comber H, Forman D, and Bray F. 2013. Cancer incidence and mortality patterns in Europe: estimates for 40 countries in 2012. European journal of cancer (Oxford, England : 1990) 49:1374-1403 DOI:10.1016/j.ejca.2012.12.027.

Fridman WH, Pagès F, Sautès-Fridman C, and Galon J. 2012. The immune contexture in human tumours: impact on clinical outcome. Nature reviews Cancer 12:298-306 DOI: $10.1038 / \mathrm{nrc} 3245$.

Haurie V, Durrieu-Gaillard S, Dumay-Odelot H, Da Silva D, Rey C, Prochazkova M, Roeder RG, Besser D, and Teichmann M. 2010. Two isoforms of human RNA polymerase III with specific functions in cell growth and transformation. Proceedings of the National Academy of Sciences of the United States of America 107:4176-4181 DOI:10.1073/pnas.0914980107.

Kashif Khan M, Ahmed I, and Raza SJ. 2014. Factors effecting recurrence and progression of high grade non invasive bladder cancer treated by intravesical BCG. Pakistan journal of medical sciences 30:326-330 DOI: 10.12669/pjms.302.4117.

Khattar E, Kumar P, Liu CY, Akıncılar SC, Raju A, Lakshmanan M, Maury JJP, Qiang Y, Li S, Tan EY, Hui KM, Shi M, Loh YH, and Tergaonkar V. 2016. Telomerase reverse transcriptase promotes cancer cell proliferation by augmenting tRNA expression. The Journal of clinical investigation 126:4045-4060 DOI:10.1172/JCI86042.

Li B, Severson E, Pignon J-C, Zhao H, Li T, Novak J, Jiang P, Shen H, Aster JC, Rodig S, Signoretti S, Liu JS, and Liu XS. 2016. Comprehensive analyses of tumor immunity: implications for cancer immunotherapy. Genome biology 17:174 DOI: 10.1186/s13059016-1028-7. 
374

375

376

377

378

379

380

381

382

383

384

385

386

387

388

389

390

391

392

393

394

395

396

397

398

399

400

401

402

403

404

405

406

407

408

409

410

411

412

413

Li T, Fan J, Wang B, Traugh N, Chen Q, Liu JS, Li B, and Liu XS. 2017. TIMER: A Web Server for Comprehensive Analysis of Tumor-Infiltrating Immune Cells. Cancer research 77:e108-e110 DOI: 10.1158/0008-5472.CAN-17-0307.

Liberzon A, Birger C, Thorvaldsdóttir H, Ghandi M, Mesirov JP, and Tamayo P. 2015. The Molecular Signatures Database (MSigDB) hallmark gene set collection. Cell systems 1:417-425 DOI: 10.1016/j.cels.2015.12.004.

Lund RJ, Rahkonen N, Malonzo M, Kauko L, Emani MR, Kivinen V, Närvä E, Kemppainen E, Laiho A, Skottman H, Hovatta O, Rasool O, Nykter M, Lähdesmäki H, and Lahesmaa R. 2017. RNA Polymerase III Subunit POLR3G Regulates Specific Subsets of PolyA and SmallRNA Transcriptomes and Splicing in Human Pluripotent Stem Cells. Stem cell reports 8:1442-1454 DOI:10.1016/j.stemcr.2017.04.016.

Masugi Y, Abe T, Ueno A, Fujii-Nishimura Y, Ojima H, Endo Y, Fujita Y, Kitago M, Shinoda M, Kitagawa Y, and Sakamoto M. 2019. Characterization of spatial distribution of tumorinfiltrating CD8 T cells refines their prognostic utility for pancreatic cancer survival. Modern pathology : an official journal of the United States and Canadian Academy of Pathology, Inc 32:1495-1507 DOI: 10.1038/s41379-019-0291-z.

Morales A, Eidinger D, and Bruce AW. 1976. Intracavitary Bacillus Calmette-Guerin in the treatment of superficial bladder tumors. The Journal of urology 116:180-183 DOI: 10.1016/s0022-5347(17)58737-6.

Naito Y, Saito K, Shiiba K, Ohuchi A, Saigenji K, Nagura H, and Ohtani H. 1998. CD8+ T cells infiltrated within cancer cell nests as a prognostic factor in human colorectal cancer. Cancer research 58:3491-3494.

Petrie JL, Swan C, Ingram RM, Frame FM, Collins AT, Dumay-Odelot H, Teichmann M, Maitland NJ, and White RJ. 2019. Effects on prostate cancer cells of targeting RNA polymerase III. Nucleic acids research 47:3937-3956 DOI: 10.1093/nar/gkz128.

Pfannstiel C, Strissel PL, Chiappinelli KB, Sikic D, Wach S, Wirtz RM, Wullweber A, Taubert H, Breyer J, Otto W, Worst T, Burger M, Wullich B, Bolenz C, Fuhrich N, Geppert CI, Weyerer V, Stoehr R, Bertz S, Keck B, Erlmeier F, Erben P, Hartmann A, Strick R, and Eckstein M. 2019. The Tumor Immune Microenvironment Drives a Prognostic Relevance That Correlates with Bladder Cancer Subtypes. Cancer immunology research 7:923-938 DOI: 10.1158/2326-6066.CIR-18-0758.

Robinson MD, McCarthy DJ, Smyth GK. 2010. edgeR: a Bioconductor package for differential expression analysis of digital gene expression data. Bioinformatics 26:139-140 DOI: 10.1093/bioinformatics/btp616.

Shariat SF, Youssef RF, Gupta A, Chade DC, Karakiewicz PI, Isbarn H, Jeldres C, Sagalowsky AI, Ashfaq R, and Lotan Y. 2010. Association of angiogenesis related markers with bladder cancer outcomes and other molecular markers. The Journal of urology 183:17441750 DOI: 10.1016/j.juro.2010.01.018.

Siegel RL, Miller KD, and Jemal A. 2020. Cancer statistics, 2020. CA: a cancer journal for clinicians 70: 7-30 DOI: 10.3322/caac.21590. 
414 Stein JP, Lieskovsky G, Cote R, Groshen S, Feng AC, Boyd S, Skinner E, Bochner B,

415

416

417

418

419

420

421

422

423

424

425

426

427

428

429

430

431

432

433

434

435

436

437

438

439

440

441

442

443

444

445

446

447

448

449 Thangathurai D, Mikhail M, Raghavan D, and Skinner DG. 2001. Radical cystectomy in the treatment of invasive bladder cancer: long-term results in 1,054 patients. Journal of clinical oncology : official journal of the American Society of Clinical Oncology 19:666675 DOI: 10.1200/JCO.2001.19.3.666.

Subramanian A, Tamayo P, Mootha VK, Mukherjee S, Ebert BL, Gillette MA, Paulovich A, Pomeroy SL, Golub TR, Lander ES, and Mesirov JP. 2005. Gene set enrichment analysis: a knowledge-based approach for interpreting genome-wide expression profiles.

Proceedings of the National Academy of Sciences of the United States of America 102:15545-15550 DOI: 10.1073/pnas.0506580102.

Thompson RH, Dong H, and Kwon ED. 2007. Implications of B7-H1 expression in clear cell carcinoma of the kidney for prognostication and therapy. Clinical cancer research : an official journal of the American Association for Cancer Research 13:709s-715s DOI: 10.1158/1078-0432.CCR-06-1868.

Tilley SK, Kim WY, and Fry RC. 2017. Analysis of bladder cancer tumor CpG methylation and gene expression within The Cancer Genome Atlas identifies as a prognostic biomarker for basal-like bladder cancer. American journal of cancer research 7:1850-1862.

Topalian SL, Drake CG, and Pardoll DM. 2015. Immune checkpoint blockade: a common denominator approach to cancer therapy. Cancer cell 27:450-461 DOI: 10.1016/j.ccell.2015.03.001.

Unoki M, Kelly JD, Neal DE, Ponder BAJ, Nakamura Y, and Hamamoto R. 2009. UHRF1 is a novel molecular marker for diagnosis and the prognosis of bladder cancer. British journal of cancer 101:98-105 DOI: 10.1038/sj.bjc.6605123.

Vihervuori H, Autere TA, Repo H, Kurki S, Kallio L, Lintunen MM, Talvinen K, and Kronqvist P. 2019. Tumor-infiltrating lymphocytes and CD8 T cells predict survival of triplenegative breast cancer. Journal of cancer research and clinical oncology 145:3105-3114 DOI: 10.1007/s00432-019-03036-5.

Witjes JA, Bruins HM, Cathomas R, Compérat EM, Cowan NC, Gakis G, Hernández V, Linares Espinós E, Lorch A, Neuzillet Y, Rouanne M, Thalmann GN, Veskimäe E, Ribal MJ, and van der Heijden AG. 2020. European Association of Urology Guidelines on Muscleinvasive and Metastatic Bladder Cancer: Summary of the 2020 Guidelines. European urology S0302-2838(20)30230-X DOI: 10.1016/j.eururo.2020.03.055.

Wong RC-B, Pollan S, Fong H, Ibrahim A, Smith EL, Ho M, Laslett AL, and Donovan PJ. 2011. A novel role for an RNA polymerase III subunit POLR3G in regulating pluripotency in human embryonic stem cells. Stem cells (Dayton, Ohio) 29:1517-1527 DOI: 10.1002/stem.714. 
Figure 1

POLR3G expression in different disease states and survival curve of patients with TCC.

(A) Differential expressions of POLR3G in multiple cancer types analyzed by TIMER. P value significant codes: $0 \leq * * *<0.001 \leq * *<0.01 \leq *<0.05 \leq .<0.1$ (B) RNA-Seq differential expression analysis in TCC tissues and normal bladder tissues. (C) Differential expressions of POLR3G in T24 cells compared to SV-HUC-1 cells. (D) Impact of POLR3G expression on overall survival of patients with TCC in TCGA. 


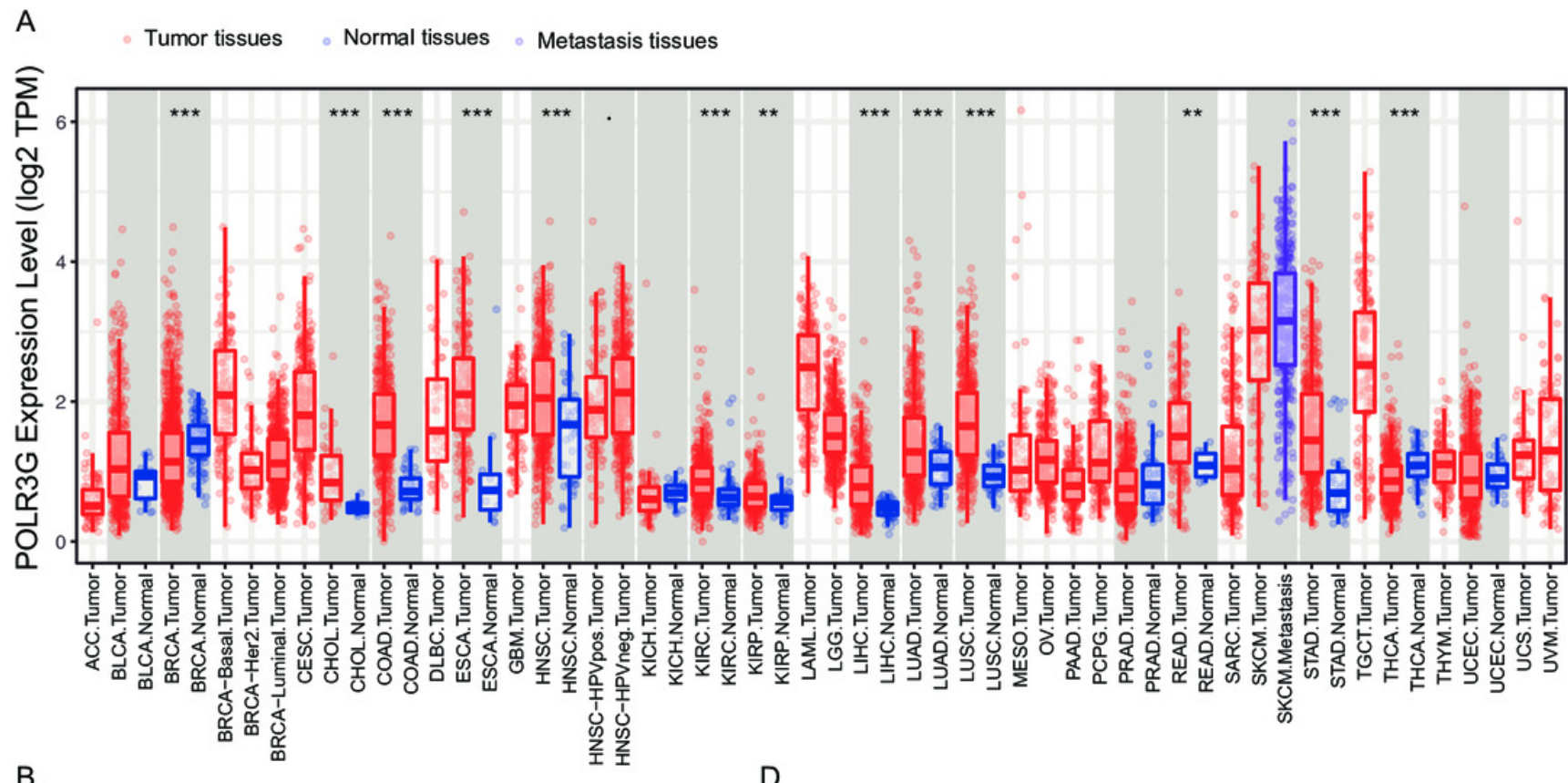

B

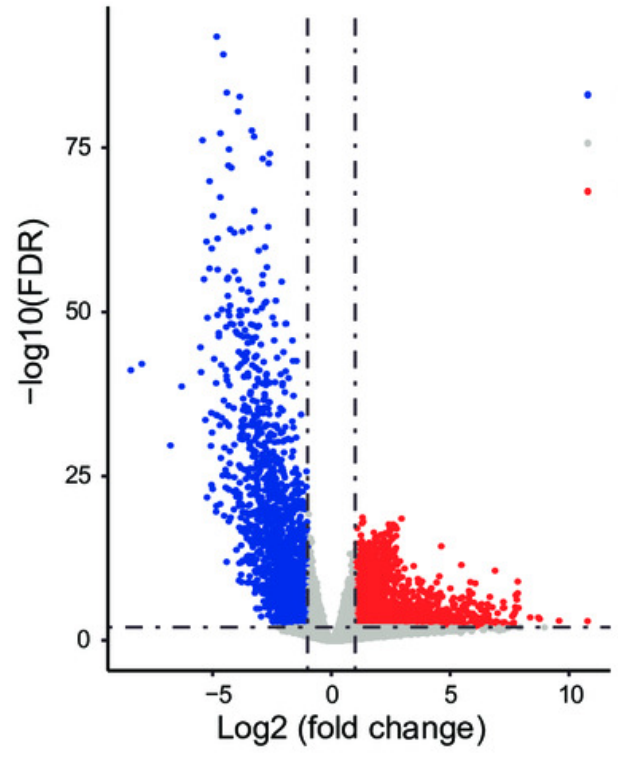

C

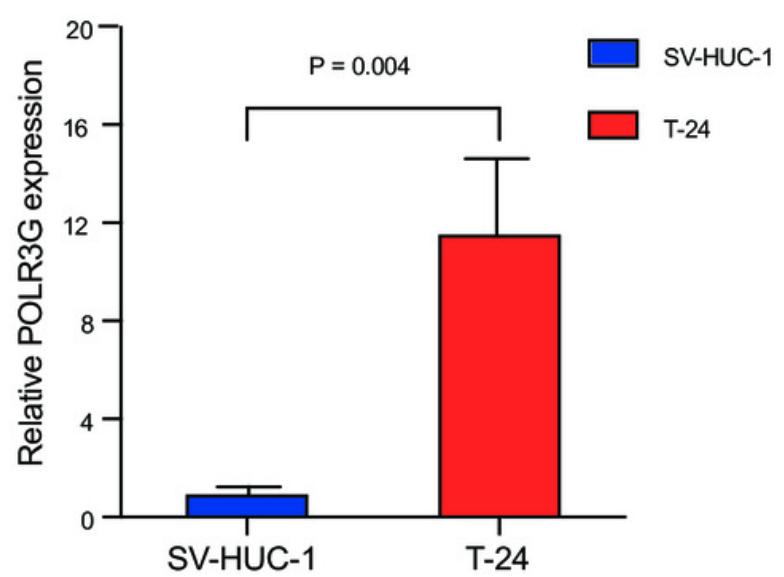

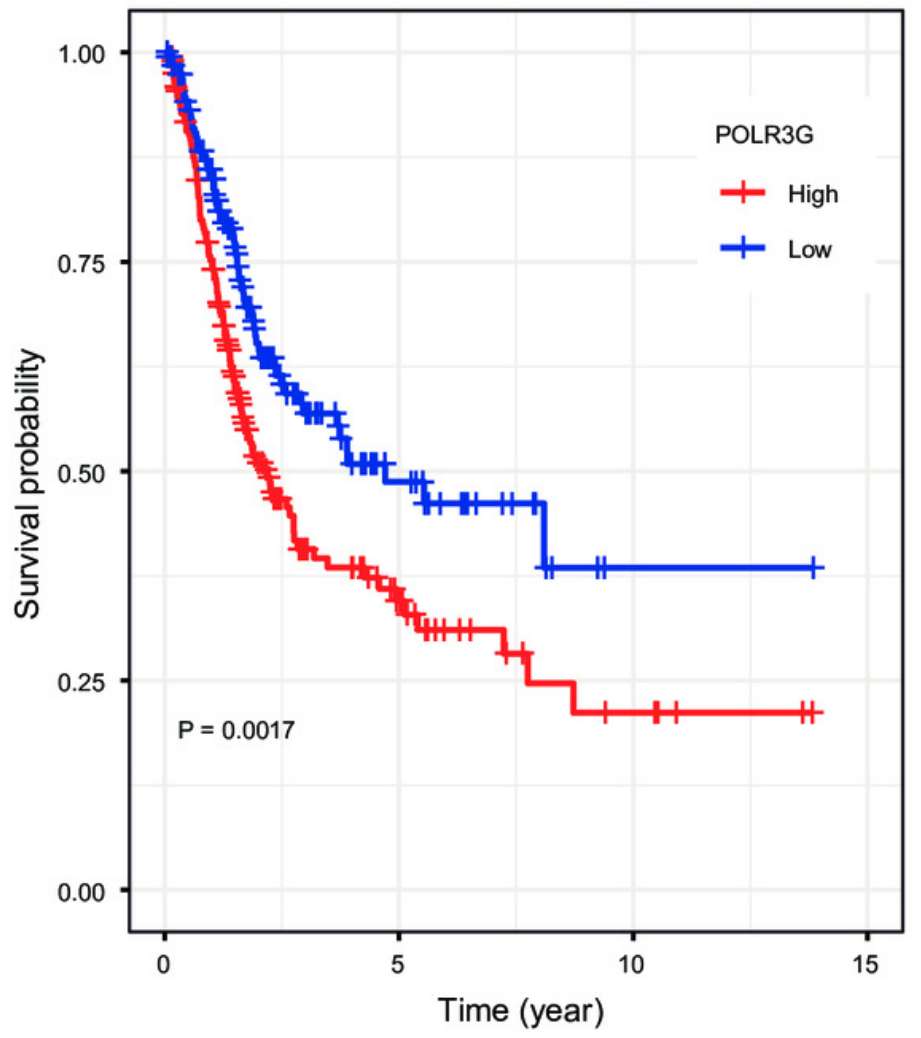

Number at risk

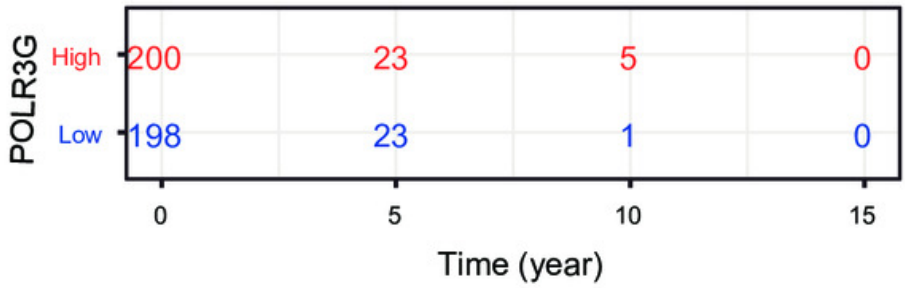


Figure 2

Association with POLR3G expression and clinicopathological characteristics.

Clinicopathologic characteristics included were listed as followed: (A) T classification. (B)

Pathological stage. (C) Tumor status. (D) Tumor subtype. (E) Race. (F) Age at diagnosis. (G)

Gender. (H) Lymph node metastasis. (I) Distant metastasis. 


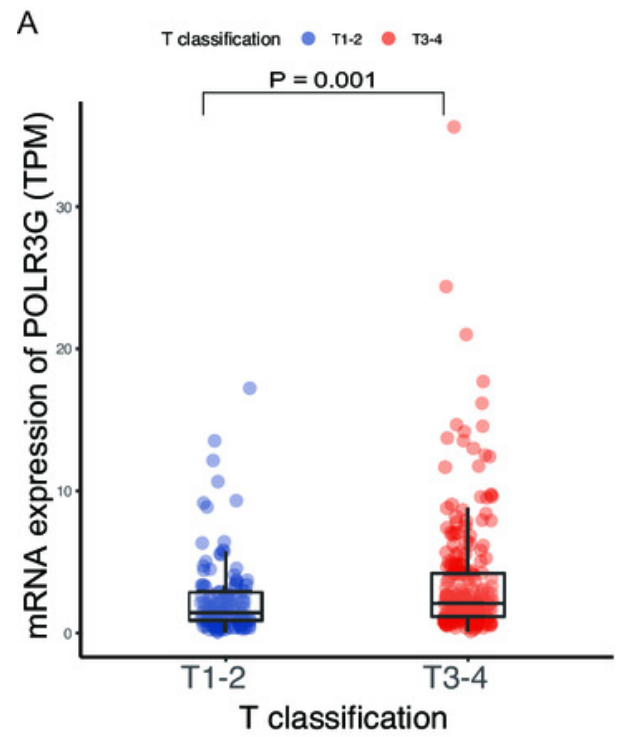

D
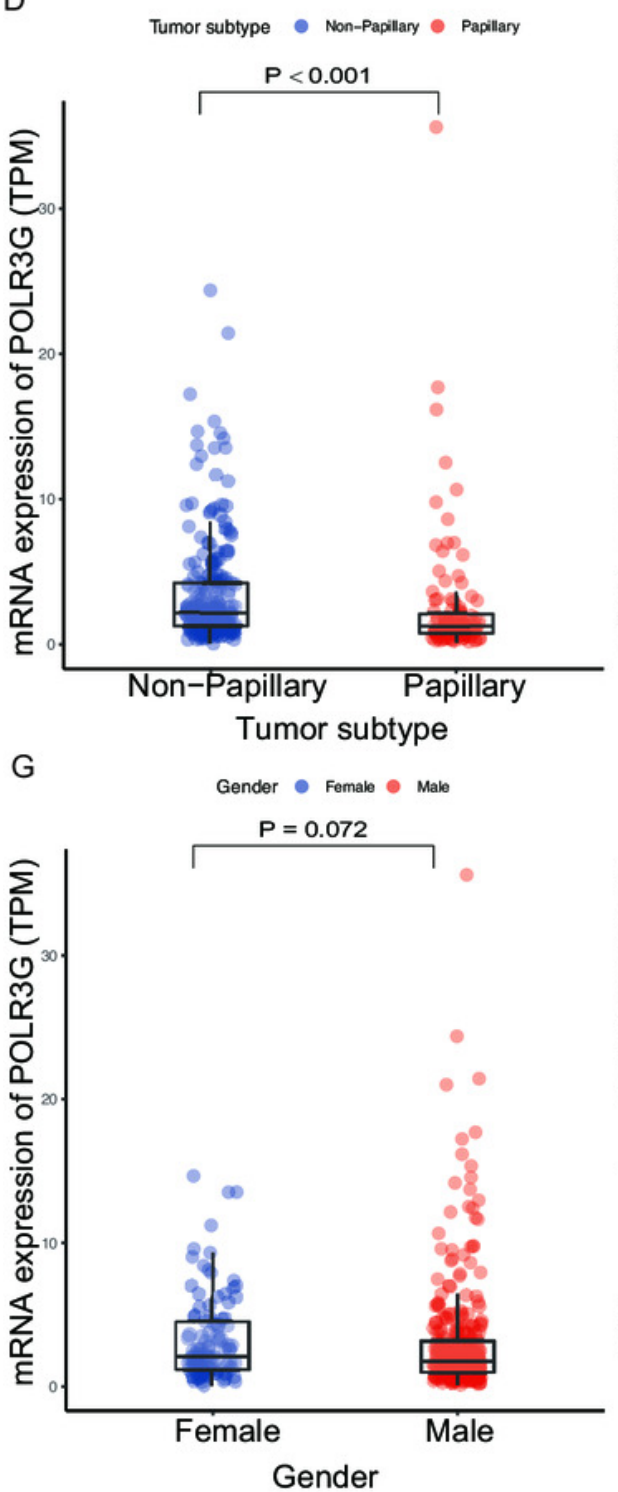
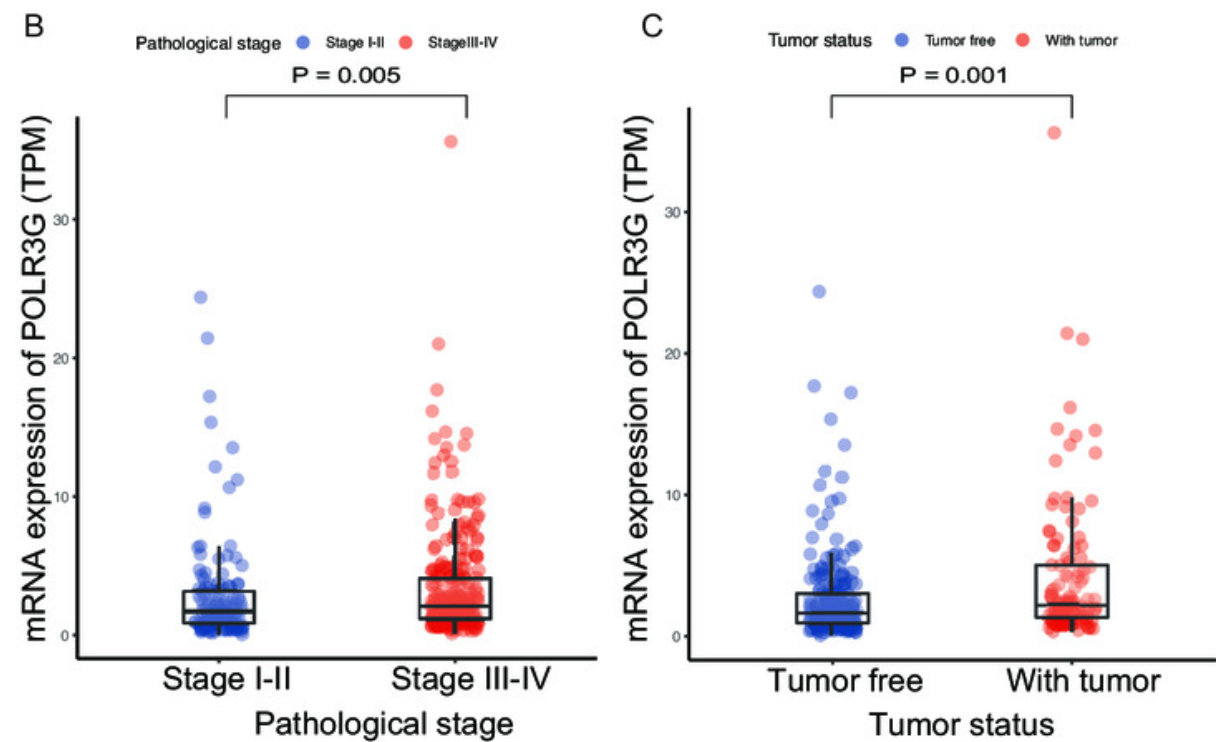

E
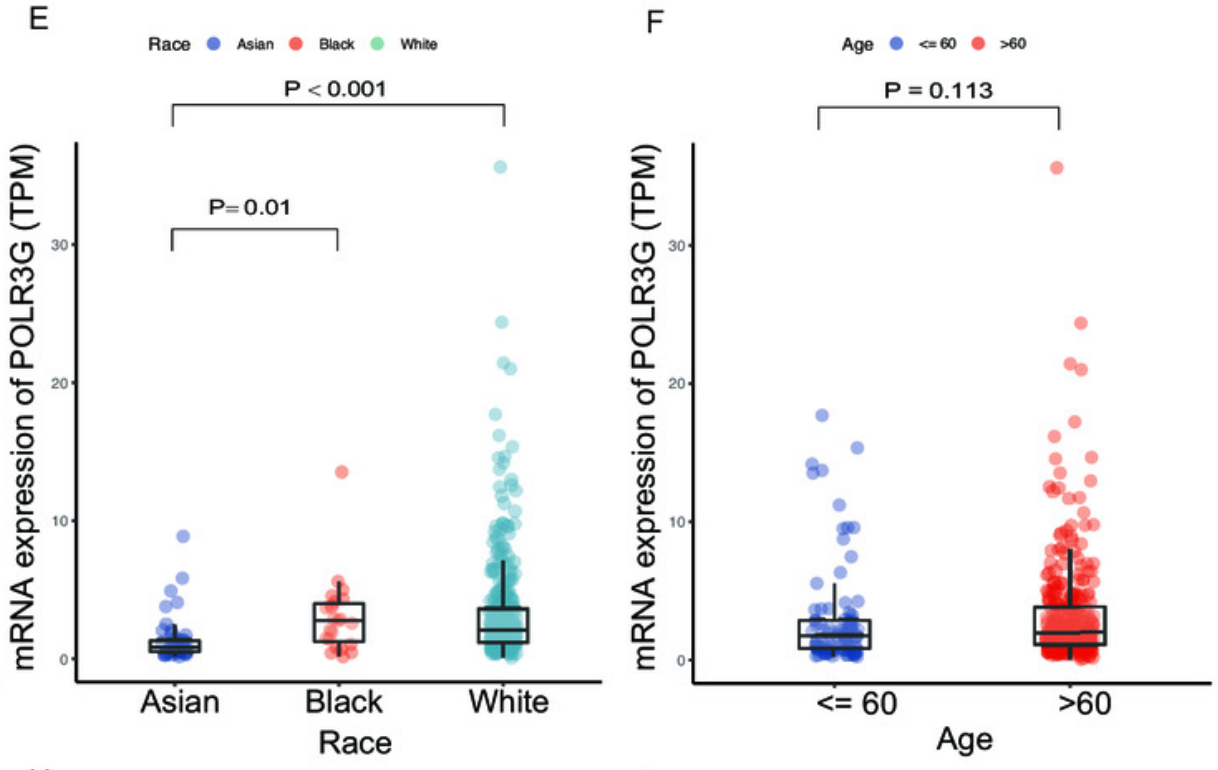

$\mathrm{H}$
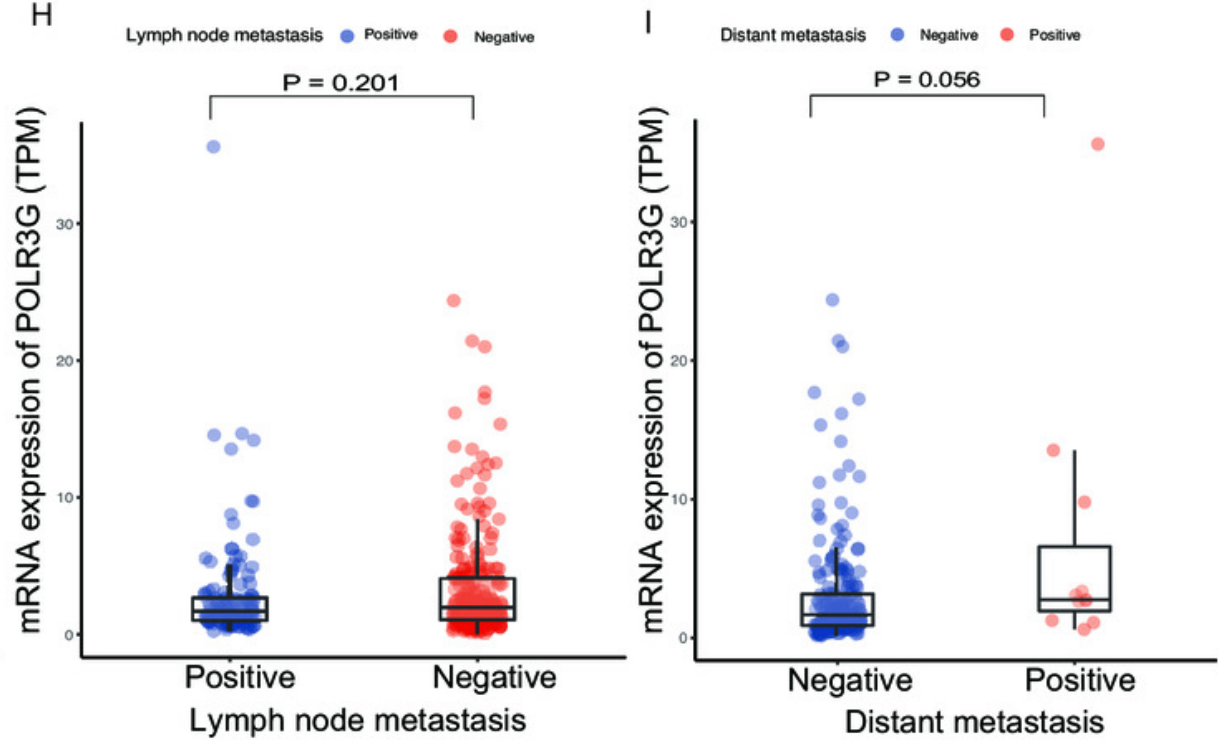
Figure 3

Multivariate Cox analysis of POLR3G expression and other clinicopathological characteristics.

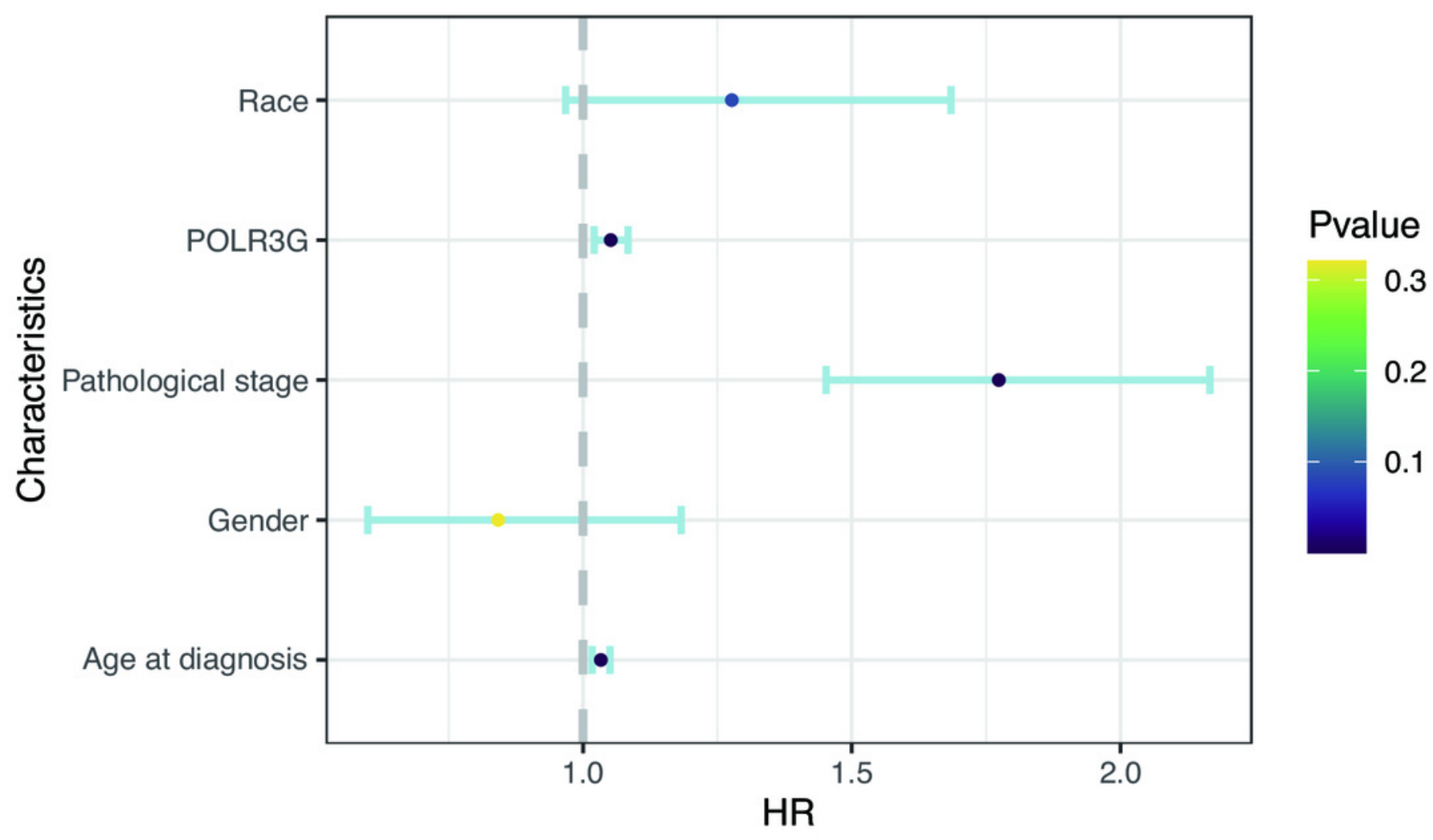


Figure 4

Enrichment plots from gene set enrichment analysis.

Gene sets enriched in POLR3G high phenotype: (A) Mitotic spindle. (B) Hypoxia . (C) Kras signaling up. (D) PI3K-AKT-mTOR signaling. (E) IL6-JAK-STATS3 signaling. (F) mTORC1 signaling. (G) TNF- $\alpha$ signaling via NF-KB. (H) inflammation response. (I) Myc targets v1. 

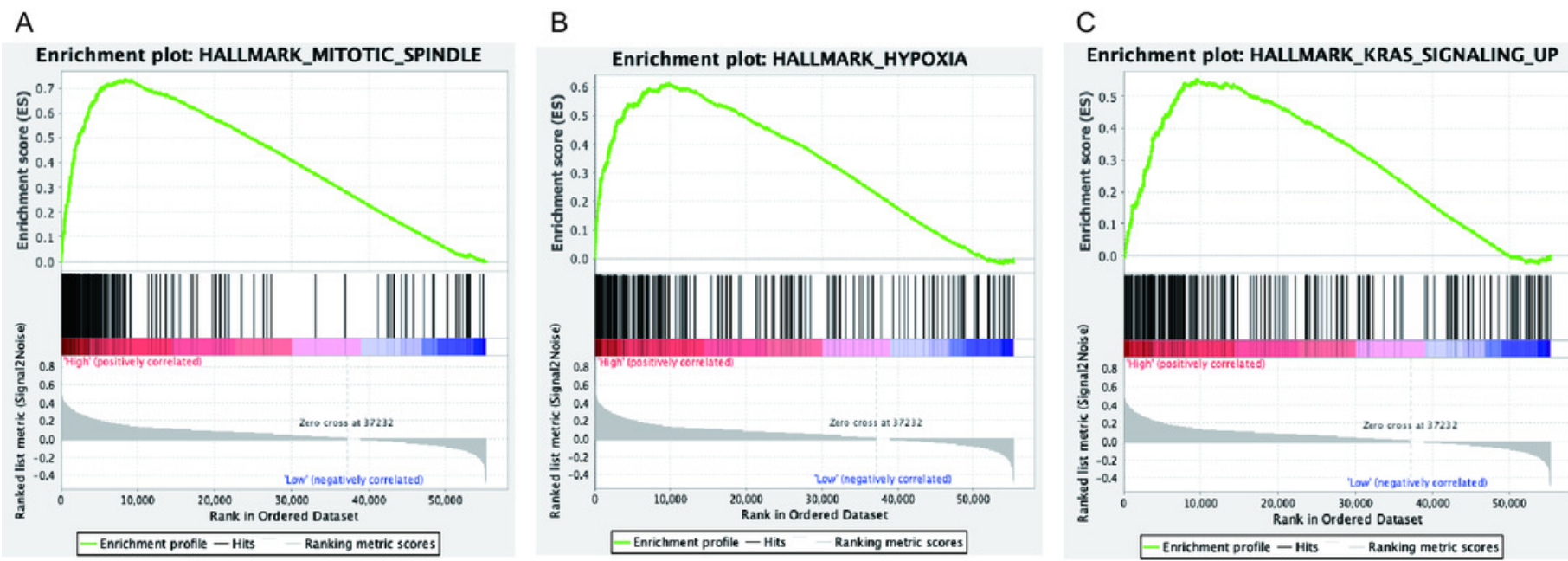

D

E

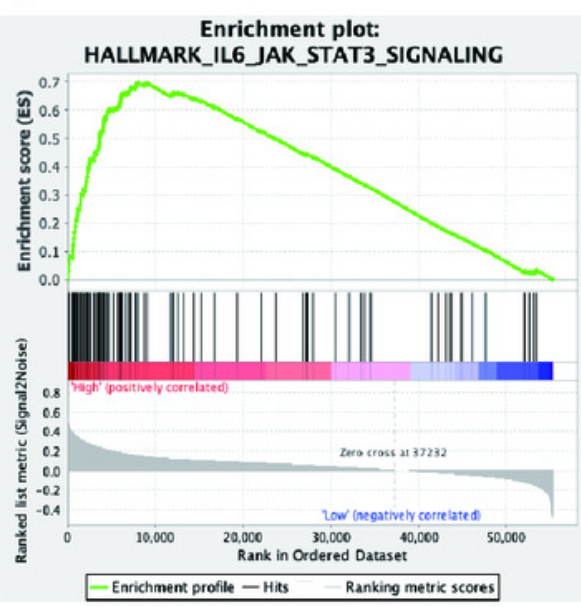

$\mathrm{H}$

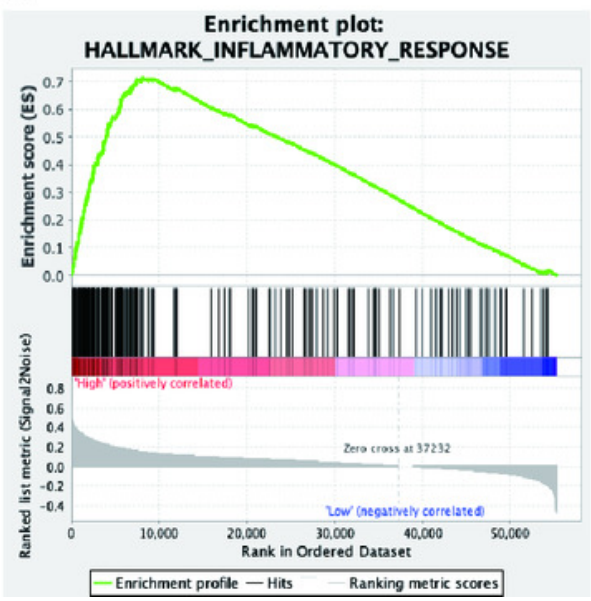

$\mathrm{F}$

Enrichment plot: HALLMARK_MTORC1_SIGNALING

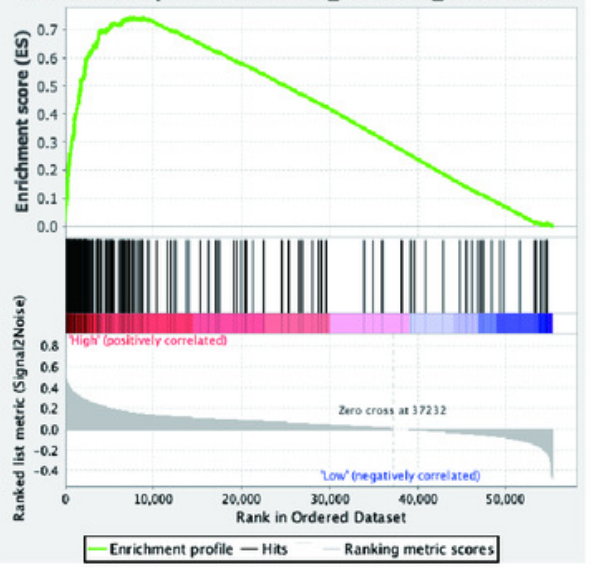

I

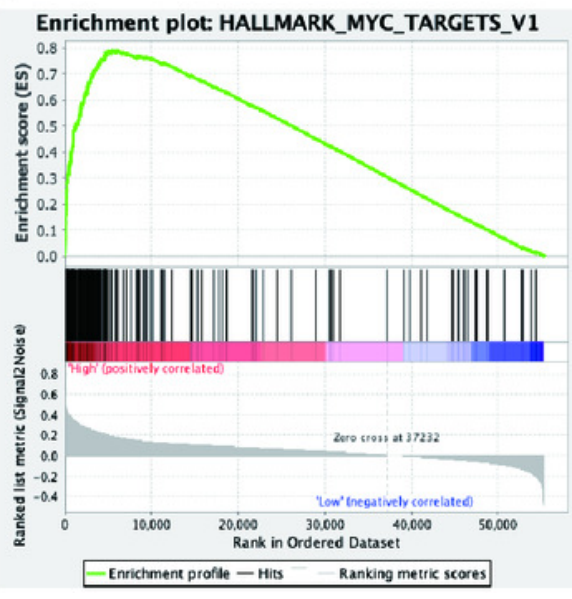


Figure 5

Correlation of POLR3G expression with immune cell infiltration and immune checkpoint molecule expression by TIMER.

(A) Correlation of immune cell infiltration with prognoses of patients with TCC. (B) Correlation of POLR3G expression with immune cell infiltration. (C) Correlation of POLR3G expression with immune checkpoint molecule expression.
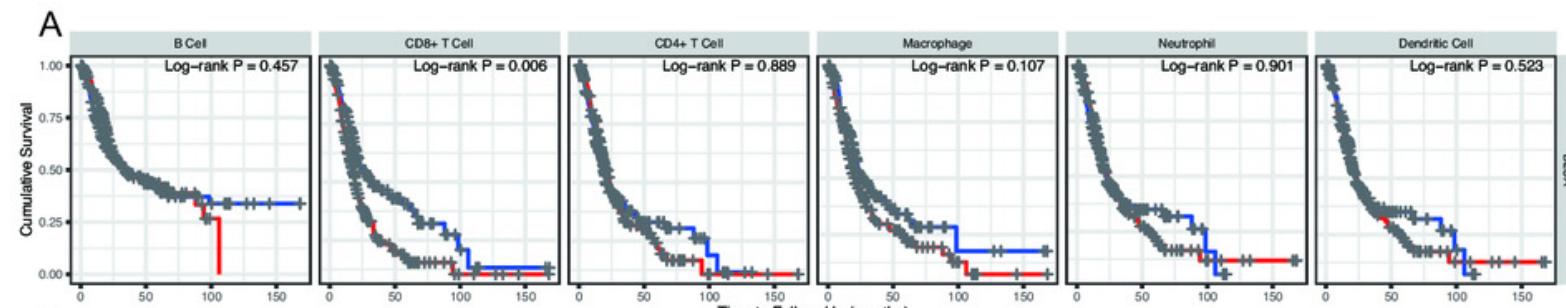

Level

- Low (Botom 50\%)

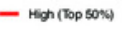
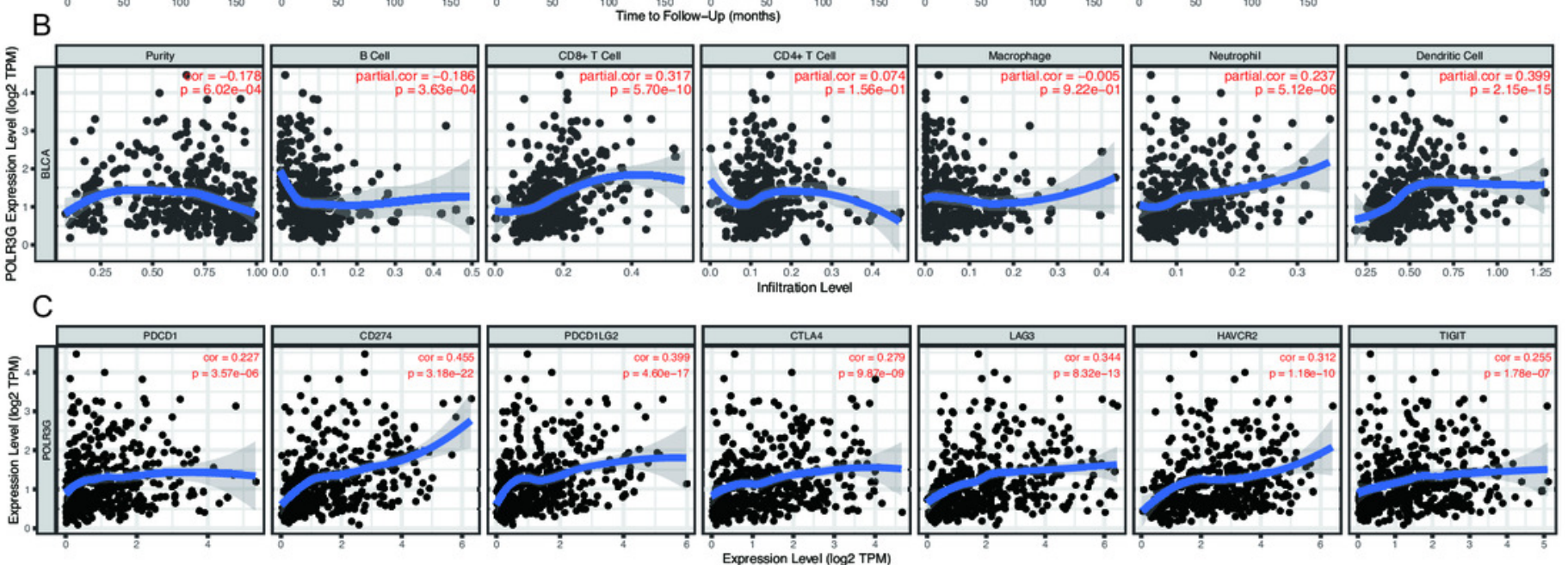


\section{Table 1 (on next page)}

Patient characteristics of patients with TCC in TCGA

TCC, Transitional cell carcinoma; TCGA, The Cancer Genome Atlas 


\begin{tabular}{|c|c|c|}
\hline Clinical characteristics & Total $(n=404)$ & Percentage $(\%)$ \\
\hline \multicolumn{3}{|l|}{ Age at diagnosis (y) } \\
\hline$\leq 60$ & 86 & 21.34 \\
\hline$>60$ & 317 & 78.66 \\
\hline \multicolumn{3}{|l|}{ Gender } \\
\hline Female & 105 & 25.99 \\
\hline Male & 299 & 74.01 \\
\hline \multicolumn{3}{|l|}{ Race } \\
\hline White & 322 & 82.99 \\
\hline Asian & 43 & 11.08 \\
\hline Black or African American & 23 & 5.93 \\
\hline \multicolumn{3}{|l|}{ Tumor status } \\
\hline With tumor & 115 & 36.28 \\
\hline Tumor free & 202 & 63.72 \\
\hline \multicolumn{3}{|l|}{ Tumor subtype } \\
\hline Papillary & 110 & 32.93 \\
\hline Non-papillary & 224 & 67.07 \\
\hline \multicolumn{3}{|l|}{$\mathrm{T}$ classification } \\
\hline $\mathrm{T} 1$ & 3 & 0.81 \\
\hline $\mathrm{T} 2$ & 119 & 32.08 \\
\hline T3 & 192 & 51.75 \\
\hline $\mathrm{T} 4$ & 57 & 15.36 \\
\hline \multicolumn{3}{|l|}{ Lymph node metastasis } \\
\hline Negative & 234 & 64.46 \\
\hline Positive & 129 & 35.54 \\
\hline \multicolumn{3}{|l|}{ Distant metastasis } \\
\hline Negative & 194 & 94.63 \\
\hline Positive & 11 & 5.37 \\
\hline \multicolumn{3}{|l|}{ Pathological stage } \\
\hline Stage I & 2 & 0.50 \\
\hline Stage II & 129 & 32.09 \\
\hline Stage III & 137 & 34.08 \\
\hline Stage IV & 134 & 33.33 \\
\hline
\end{tabular}


Table 2 (on next page)

Univariate and multivariate Cox regression analysis of overall survival.

$\mathrm{HR}$, hazard ratio; $\mathrm{Cl}$, confidence interval 


\begin{tabular}{|c|c|c|c|c|c|}
\hline \multirow{2}{*}{$\begin{array}{l}\text { Characteristics } \\
\qquad(\mathrm{n}=381)\end{array}$} & \multicolumn{2}{|c|}{ Univariate analysis } & $\sqsubset$ & \multicolumn{2}{|c|}{ Multivariate analysis } \\
\hline & $\operatorname{HR}(95 \% \mathrm{CI})$ & $\mathrm{P}$ value & $\sqsubset$ & $\operatorname{HR}(95 \% \mathrm{CI})$ & $\mathrm{P}$ value \\
\hline Age at diagnosis & $1.03(1.02-1.05)$ & $<0.001$ & & $1.03(1.02-1.05)$ & $<0.001$ \\
\hline Gender & $0.82(0.59-1.16)$ & 0.263 & & $0.84(0.60-1.18)$ & 0.321 \\
\hline Race & $1.04(0.78-1.38)$ & 0.783 & & $1.28(0.97-1.68)$ & 0.084 \\
\hline Pathological stage & $1.71(1.41-2.08)$ & $<0.001$ & & $1.77(1.45-2.17)$ & $<0.001$ \\
\hline POLR3G expression & $1.04(1.01-1.07)$ & 0.021 & $\sqsubset$ & $1.05(1.02-1.08)$ & 0.001 \\
\hline
\end{tabular}

1 


\section{Table 3 (on next page)}

Gene sets enriched in POLR3G high expression phenotype

NES, normalized enrichment score; NOM P value, nominal P value; FDR, false discovery rate 


\begin{tabular}{|c|c|c|c|}
\hline Gene set & NES & NOM P value & FDR q value \\
\hline IL6 JAK STAT3 signaling & 2.83 & $<0.001$ & $<0.001$ \\
\hline Allograft rejection & 2.72 & $<0.001$ & $<0.001$ \\
\hline mTORC1 signaling & 2.7 & $<0.001$ & $<0.001$ \\
\hline Protein secretion & 2.69 & $<0.001$ & $<0.001$ \\
\hline Inflammatory response & 2.67 & $<0.001$ & $<0.001$ \\
\hline Glycolysis & 2.58 & $<0.001$ & $<0.001$ \\
\hline Heme metabolism & 2.56 & $<0.001$ & $<0.001$ \\
\hline Mitotic spindle & 2.53 & $<0.001$ & $<0.001$ \\
\hline Androgen response & 2.46 & $<0.001$ & $<0.001$ \\
\hline Interferon- $\gamma$ response & 2.46 & $<0.001$ & $<0.001$ \\
\hline TNF- $\alpha$ signaling via NF-kB & 2.44 & $<0.001$ & $<0.001$ \\
\hline PI3K AKT mTOR signaling & 2.42 & $<0.001$ & $<0.001$ \\
\hline G2M checkpoint & 2.36 & $<0.001$ & $<0.001$ \\
\hline Hypoxia & 2.34 & $<0.001$ & $<0.001$ \\
\hline UV response down & 2.32 & $<0.001$ & $<0.001$ \\
\hline Apical junction & 2.28 & $<0.001$ & $<0.001$ \\
\hline Kras signaling up & 2.28 & $<0.001$ & $<0.001$ \\
\hline Complement & 2.28 & $<0.001$ & $<0.001$ \\
\hline Myc targets v1 & 2.22 & $<0.001$ & $<0.001$ \\
\hline Unfolded protein response & 2.18 & $<0.001$ & 0.006 \\
\hline UV response up & 2.08 & $<0.001$ & 0.011 \\
\hline IL2 STAT5 signaling & 2.06 & $<0.001$ & 0.015 \\
\hline Interferon- $\alpha$ response & 2.03 & $<0.001$ & 0.014 \\
\hline Epithelial mesenchymal & 2.03 & $<0.001$ & 0.014 \\
\hline E2F targets & 2.03 & $<0.001$ & 0.013 \\
\hline Apoptosis & 2.02 & $<0.001$ & 0.013 \\
\hline TGF- $\beta$ signaling & 2.02 & $<0.001$ & 0.012 \\
\hline Adipogenesis & 2 & $<0.001$ & 0.012 \\
\hline Coagulation & 1.96 & $<0.001$ & 0.015 \\
\hline Reactive oxygen species & 1.88 & $<0.001$ & 0.026 \\
\hline P53 pathway & 1.87 & $<0.001$ & 0.03 \\
\hline Fatty acid metabolism & 1.87 & $<0.001$ & 0.029 \\
\hline Estrogen response early & 1.84 & $<0.001$ & 0.028 \\
\hline Myc targets v2 & 1.83 & $<0.001$ & 0.027 \\
\hline DNA repair & 1.77 & $<0.001$ & 0.035 \\
\hline Oxidative phosphorylation & 1.77 & $<0.001$ & 0.034 \\
\hline Angiogenesis & 1.66 & $<0.001$ & 0.056 \\
\hline Apical surface & 1.62 & $<0.001$ & 0.057 \\
\hline Spermatogenesis & 1.59 & $<0.001$ & 0.065 \\
\hline Estrogen response late & 1.57 & $<0.001$ & 0.076 \\
\hline Cholesterol homeostasis & 1.46 & $<0.001$ & 0.087 \\
\hline
\end{tabular}

